\title{
Comparison of Collum Angle of Maxillary Central Incisors in Different Incisor Relationships
}

\author{
Zahra Khalid, Kashif Iqbal, Sana Khalid, Aima Riaz and Abdullah Jan \\ Armed Forces Institute of Dentistry, National University of Medical Sciences, Rawalpindi, Pakistan
}

\begin{abstract}
Objective: To compare the collum angle of maxillary central incisors in patients with different incisor relationships.

Study Design: Comparative, cross-sectional study.

Place and Duration of Study: Department of Orthodontics, Armed Forces Institute of Dentistry, Combined Military Hospital, Rawalpindi, from March to October 2019.

Methodology: Patient data was obtained from the Department of Orthodontics, Armed Forces Institute of Dentistry, Rawalpindi. One Hundred patients were included in the study, which were divided into four groups, 25 patients in each group, based on incisor relationship, i.e. class I, class II div 1, class II div 2, and class III. The collum angle of maxillary central incisors was then measured twice by a single investigator on lateral cephalograms. Sagittal skeletal relationship, age and gender were noted. Molar relationship of the above groups was also recorded from their respective casts.

Results: Out of the 100 patients, 31 were males, while 69 were females. Mean collum angles of maxillary central incisors for class I, class II div 1, class II div 2 , and class III were $5.12 \pm 3.78,6.09 \pm 4.57,15.02 \pm 7.99$, and $6.94 \pm 3.80$, respectively. Collum angle of class II div 2 incisor relationship was significantly greater than other classes $(p<0.05)$. Collum angle of incisors of casts with class II molar relationship also exhibited the same trend, i.e. a greater angle than other groups $(p=0.002)$. There was no significant difference in collum angle among different sagittal skeletal relationships $(p=0.476)$, between males and females ( $p$-value .731) and among different age groups $(p=0.194)$. ICC showed good agreement between the readings of collum angle (Crohnbachs Alpha .997).

Conclusion: Class II div 2 incisor relationship had a significantly greater collum angle than other groups.
\end{abstract}

Key Words: Collum angle, Incisor inclination, Crown to root angle, Class II div 2 malocclusion.

How to cite this article: Khalid Z, Iqbal K, Khalid S, Riaz A, Jan A. Comparison of Collum Angle of Maxillary Central Incisors in Different Incisor Relationships. J Coll Physicians Surg Pak 2020; 30(05):471-475. DOI: https://doi.org/10.29271/jcpsp.2020.05.471.

\section{INTRODUCTION}

Dental anatomy has far reaching effects on attainment of optimum esthetics and stable occlusal relationship. ${ }^{1}$ Andrews developed six keys of occlusion for the establishment of normal occlusion. According to him, the third most important factor for establishment of proper occlusion is labiolingual inclination of teeth, which is depicted generally as long axis of tooth with reference to palatal plane or cranial base. By convention, it is generally perceived that longitudinal axis of the crown coincides with the longitudinal axis of root. However, if we observe critically, it becomes evident that the crown of maxillary incisors is angled in a peculiar way to the root of tooth. ${ }^{2}$ Collum angle explains this variation of crown to root angulation.

Morphological variations of the maxillary central incisors influence both the active as well as retention phase of orthodontic treatment in several ways.

Correspondence to: Dr. Kashif Iqbal, Armed Forces Institute of Dentistry, National University of Medical Sciences,

Rawalpindi, Pakistan

E-mail: kashif_0105@yahoo.com

Received: March 13, 2020; Revised: May 08, 2020;

Accepted: May 26, 2020

DOI: https://doi.org/10.29271/jcpsp.2020.05.471

Deviation in the crown root angulation is a factor that can affect the force vector, axial inclination and magnitude of movement that can be achieved when the tooth is moved orthodontically especially along its vertical plane i.e.; during its intrusion or extrusion. ${ }^{3}$ In restorative dentistry, while restoring a tooth with large crown to root angle, core build-ups may be a concern. When an implant is placed adjacent to an incisor with an increased collum angle or replaces a tooth which had an increased collum angle, implant with angledabutmentmight be placed to achievea harmonious line of occlusion. ${ }^{4}$ Therefore, it is important to know the collum angle and its variation in such cases for successful planning and implementation of treatment.

Previously, an increased collum angle has been shown in class II div 2 malocclusions; but correlation between collum angle and all four types of incisorrelationships and three types of molarrelationships was not considered, especially in Pakistani population. ${ }^{5}$

The aim of the current study was to compare the collum angle of maxillary central incisors in different types of malocclusion, based on incisor relationships on lateral cephalogram and molar relationships on casts. That would help orthodontic movements to be accomplished within the boundaries of surrounding bone.

\section{METHODOLOGY}

Ethical approval was granted by the Ethical Committee of Armed Forces Institute of Dentistry (IRB Form No. 905/Trg-ABP 1K2). It was a cross-sectional comparative study conducted on the patients' data from the Department of Orthodontics, from March 
to October 2019. Sample size was calculated, utilising the nonprobability consecutive sampling technique and by using a software G*Power. By keeping the value of $\alpha$ as $0.05, \beta$ as 0.1 and effect size as 0.54 , a sample size of 14 per group was calculated. However, a sample size of 25 per group was used, making a total sample size of 100 . The study included patients falling in the age range of 10 to 50 years, having class I, II and III incisor relationship (British standards classification), class I, II and III molar relationships (according to angle classification), and class I, II and III skeletal sagittal relationship determined by the angle ANB on a lateral cephalogram. The lateral cephalograms included in the study were all digital and taken in natural head position for ensuring accuracy of determining the points. The casts selected had fully erupted, and intact incisors and molars present. Lateral cephalograms of 100 patients; 31 male and 69 female patients were analysed. The investigators categorised patients into 4 groups of malocclusion, i.e. class I, class II div 1 , class II div 2 , and class III, according to the British standards of incisor classification. Patients having primary anterior dentition, developing roots, severely rotated anterior teeth, with previous orthodontic treatment, craniofacial anomalies, and those with the radiographs of poor quality were excluded. Patients with large restorations, endo-posts, and prosthetic crowns were also excluded from the study in order to avoid any radiographic aberration.

Maxillary central incisor was traced on acetate sheet on a lateral cephalogram. Crown axis of central incisor was drawn by joining the point incisor superius (Is) to the middle point of cementoenamel junction; and root axis was traced by extrapolating the same point to the root apex. The crown to root angulation was measured between crown and root axis. The collum angle was then obtained as shown in Figure 1. A single investigator measured the collum angle on all the cephalograms. Measurements were repeated twice on a single radiograph and intraobserver reliability was assessed using intra class reliability coefficient.

Casts were analysed for their molar and incisor relationships by another investigator.

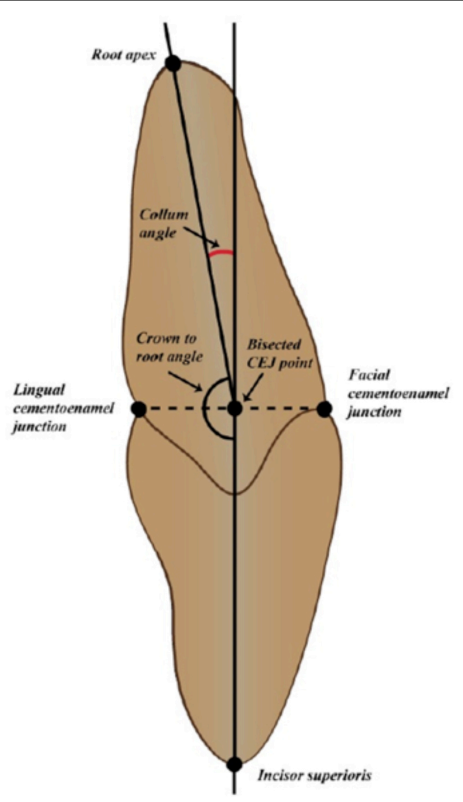

Figure 1: Collumangle measurement (180-crown to rootangle).

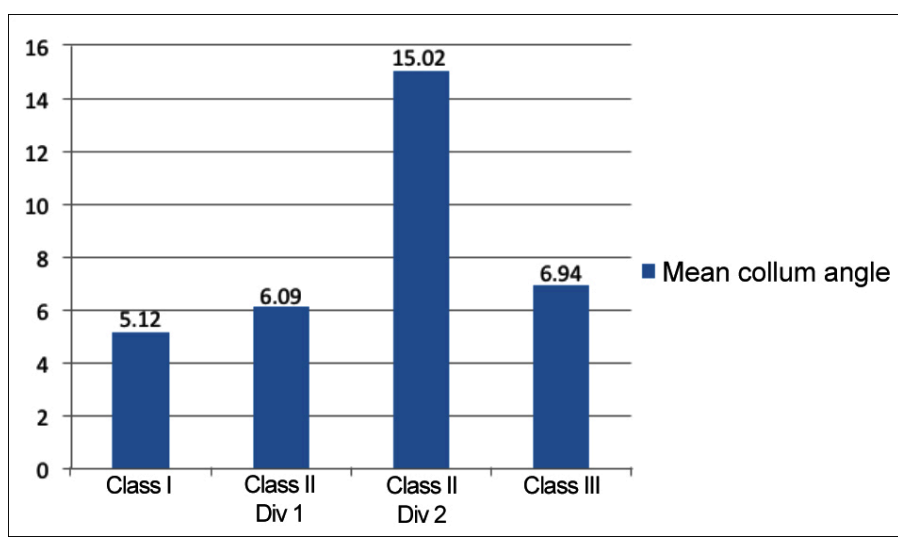

Figure 2: Histogram of mean collum angle in different classes of malocclusion.

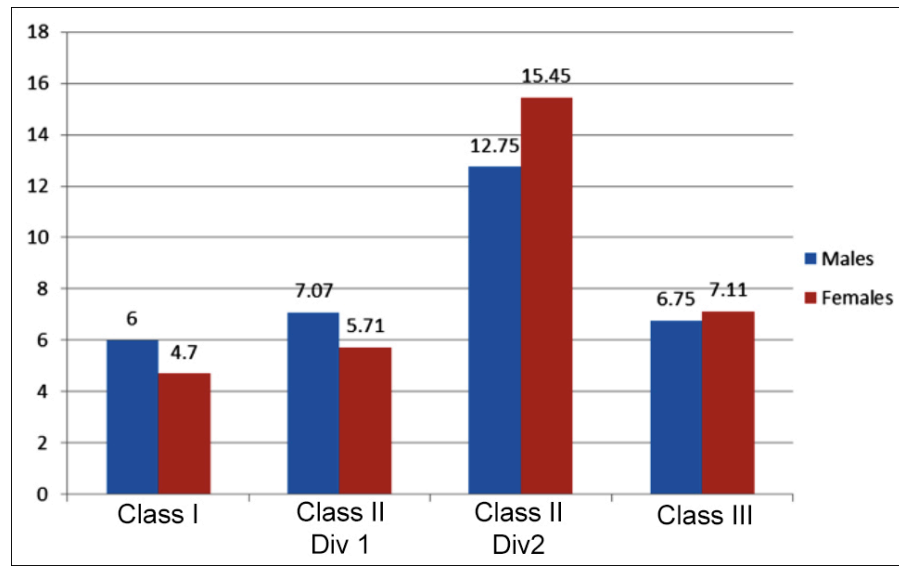

Figure 3: Comparison of collum angle among incisor classification and between genders.

Table I: Kruskal-Wallis analysis.

\begin{tabular}{|l|c|c|}
\hline Dental malocclusion & Mean & $\begin{array}{c}\text { Standard } \\
\text { deviation }\end{array}$ \\
\hline Class I & 5.1200 & 3.7839 \\
\hline Class II Div 1 & 6.0960 & 4.5754 \\
\hline Class II Div 2 & 15.0200 & 7.9993 \\
\hline Class III & 6.9400 & 3.8005 \\
\hline Total & 8.2940 & 6.5735 \\
\hline p-value & \multicolumn{2}{|c|}{$0.000 *$} \\
\hline
\end{tabular}

Table Il: Pair-wise comparison.

\begin{tabular}{|l|c|}
\hline Class I vs Class II Div 1 & 1 \\
\hline Class I vs Class II Div 2 & $0.00 *^{*}$ \\
\hline Class I vs Class III & 0.928 \\
\hline Class II div 1 vs Class II Div 2 & $0.000^{*}$ \\
\hline Class II div 1 vs Class III & 1 \\
\hline Class II div 2 vs Class lii & $0.003^{*}$ \\
\hline
\end{tabular}

Data was analysed using SPSS version 26 . Shapiro-Wilk test was used to determine normality of the data. The data was found to be non-normal. Therefore, collum angles of patients with different incisor, molar, skeletal relationships, and among age groups (4 groups from 10 to 49 years) were compared using Kruskal Wallis test and pairwise comparsion between different malocclusions were done with Mann-Whitney-U test. Comparison of collum angles between males and females was also done using Mann Whitney Utest, $p$ value of $\leq 0.05$ was considered significant 


\section{RESULTS}

Out of the 100 patients, 31 (31\%) were males and 69 (69\%) were females. The mean age of patients was $15.9^{\circ} \pm 4.8$ years. The mean collum angle of all classes of malocclusion was $8.3^{\circ} \pm 6.6$. The mean collum angle for each of incisor classification is shown in Figure 2. Gender wise mean collum angle for each of incisor classification is shown in Figure 3. Kruskal-Wallis test in conjunction with Mann-Whitney U-test showed that the collum angle of maxillary central incisors was significantly high in class II div 2 group as compared to other groups ( $<.05)$, (Table I and II). The class II div 2 group had the highest mean collum angle value of $15^{\circ}$.

Casts with class II molar relationship also had a significantly different collum angle value of incisors than those with class I and III molars $(p=0.002)$. There was no statistical difference of Collum angle across skeletal classifications $(p=0.476)$, age groups $(p=0.194)$, and between genders $(p=0.731)$. Good agreement was found between the two readings of collum angle as depicted by an intra class correlation coefficient (Cronbachs Alpha) of 0.997 .

\section{DISCUSSION}

In orthodontics, cephalometric analysis is commonly used to aid in diagnosis and treatment planning. ${ }^{6}$ In these analyses, inclination of incisors can be ascertained, which is one of the factors affecting the decision to extract or not to extract teeth during orthodontic treatment. ${ }^{7}$ Labiolingual inclination of incisors is represented by the longitudinal axis of maxillary incisor with respect to palatal plane, occlusal plane or cranial base. ${ }^{8}$ According to Bjork, the line passing through the incisor superioris and the apex of a tooth is the longitudinal axis of tooth. ${ }^{9}$ Owing to the disregard of collum angle and its impact on crown to root angulation, Bryant et al. have found this method to be suboptimal. They stated that the line passing through the central incisor should ideally bisect cementoenamel junction; but this is not what actually happens. ${ }^{11}$ Among alternative methods, one is to use lateral cephalogram template for incisor inclination. However, apart from having standardisation issues, template analysis method cannot be validated for true representation of incisal inclination. Hence, there is a need to study the variation of collum angle so that the malocclusions with incisors having a significantly angulated crown to root axis can be identified. This can then be taken into consideration while measuring the incisor inclination when performing cephalometric analysis.

The current study showed that mean collum angle of maxillary central incisors in class II div 2 incisors was significantly different as compared to other incisor classes. Collum angle was the highest for class II div 2, followed by class III, class II div 1, and class I malocclusion, respectively. The same angle was significantly different for class II molars (seen on dental casts) as compared to other molar classes. The maxillary central incisors in class II div 2 malocclusion had a mean collum angle of 15.02 \pm 7.99 . This study also showed that there was no significant difference in collum angle of class III malocclusion as compared to class I and class II div 1 malocclusion. Collum angle was also not statistically different formales as compared to females.

Variation in collum angle has been shown in various studies. One study carried out by Shailaja et al. showed that collum angle of anterior teeth to be significantly different from zero. ${ }^{12}$ In class II div 2, the collum angle of central incisors is greater, while that of lateral incisors is significantly smaller. In Pakistani population, the collum angle of the permanent maxillary central incisors differs significantly between class II div 1 and $2 .{ }^{5}$ Permanent maxillary central incisors show pronounced axial bending in class II div 2. Apart from variation among incisor classification, significant variation of collum angle occurs in malocclusions having a class II molarrelationship. ${ }^{13}$

Occlusion in three dimensions can be affected greatly by variations in dental anatomy. Variation in inclination not only affects the over jet and over bite, but also affects the intercuspation of dentition. Patients with increased collum angle present with a deep bite, which can be severe to the extent of causing trauma to the tissues palatal to the incisors. An adequate interincisal angle in normal cases, when the crown and root axis are roughly coliear, mitigates the overeruption of mandibular incisors. When the crown to root axis is angulated as in class II div 2 incisors, the interincisal crown angulation is increased. This leads to a gliding contact between upper and lower incisors which decreases axial stresses on teeth, and thus increases the bite depth. ${ }^{14}$ Thus collum angle, which depicts the axial inclination of incisors crown with respect to the root axis, is one of the key variants of intercuspal and morphological features of incisors. ${ }^{15}$

Various hypothesis have been proposed to understand the development of collum angle. Collum angle development is sometimes thought to be result of the variation of soft tissues pressures in various malocclusions; especially, lip pressure in developing class II div 2 malocclusion. ${ }^{16}$ Soft tissues can exert an influence on the position and inclination of the incisors. In class II div 1, lip-trap can cause proclination of maxillary incisors and retroclination of mandibular incisors; whereas, in class II div 2 malocclusion because of strap-like effect and high resting posture of lower lip maxillary central and/or lateral incisors can be retroclined. This high resting pressure in class II div 2 is assumed to be a cause of increase in collum angle. Hyperactivity of lips and sagittal relationship of jaws are also considered among possible reasons of collum angle variation, ${ }^{17}$ although in this study collum angle is not significantly different among different sagittal jaw relationships

Variation in crown root angulation has important implications in dental treatment. As the importance of incisors in the smile or esthetic zone is paramount so the morphologic variation in the anatomical features of maxillary central incisors is an important consideration in the attainment of an aesthetic, functional and optimal occlusion of teeth. The undeniable importance of collum angle becomes much more evident when gingival recession is seen after placement of an angled abutment on an implant. When an implant is inserted, it must be placed along the same root axis as the tooth it is replacing. If the actual tooth had a significant collum angle, then an abutment should be placed with the same collum angle to the implant as the original tooth had. In such cases, because of critical axial loading, more stresses can be generated on a single point i.e. labial gingival aspect of implants, resulting in not only gingival recession but also sometimes implant failure. ${ }^{18}$ In restorative dentistry while restoring a tooth with large crown to root angle, core build-ups may be a concern. 
Endo-post placement in teeth with large collum angles may cause difficulty in constructing the core as the post may not align along the same axis as that of the core. The post may be shortened in order to restore the crown with proper inclination. ${ }^{4}$

An increased collum angle makes the incisors appear upright. During orthodontic treatment, this is an important consideration in moving teeth or torquing them, to maintain aesthetics and for longterm retention. Crown to root angulation of maxillary central incisors may limit the degree to which the roots of these teeth can be torqued palatally. In severe cases, the root may inadvertently encroach on palatal cortical plates, causing unwarranted root resorption and dehiscence. ${ }^{19,20}$

Biomechanically, the stress strain distribution on the roots of incisors is also altered with an increased collum angle. While intruding such teeth, the centre of rotation shifts cervically thus reducing the intrusive force and introducing a moment which causes lingual tipping of incisors. This is particularly seen in lingual orthodontics. Thus, an increased torque might be incorporated while intruding such teeth. ${ }^{21}$

The findings in our study are based on two-dimensional analysis, and only central incisors are investigated. An analysis on CBCT may reveal more accurate results. Moreover, with $\mathrm{CBCT}$, a more practical and efficient method of measuring collum angle of incisors and even canines can be devised which can add valuable information to the treatment strategy. Thus from the present study, it can be clearly shown that joining incisor superius and root apex directly is not a very reliable method when determining the inclination of incisors; especially, in class 2 div II incisors. Therefore, collum angle measurement should be made a part of our day-to-day cephalometric analysis.

Apart from above mentioned considerations of diagnosis, collum angle has reasonable clinical implications so much so that correction of torque and intrusion of incisors should be done cautiously while treating incisors of class II div 2 malocclusion. While uprighting / torquing the incisors, it should be kept in mind that roots of incisors should not be placed against thick cortical plate of palate.

\section{CONCLUSION}

Maxillary central incisors in class II div 2 cases have a significantly greater collum angle than other malocclusions. Collum angle of incisors is also found to be high in cases with class II molar relation.

\section{ETHICALAPPROVAL:}

Ethical approval was granted by the Ethical Committee of Armed Forces Institute of Dentistry (IRB Form No. 905/Trg-ABP 1K2) prior to initiation of the research work.

\section{CONFLICT OF INTEREST:}

Authors declared no conflict of interest.

\section{PATIENTS' CONSENT:}

Patients' consents were not required in this study as the data was taken from the patients' records without mentioning patients' personal details or pictures.

\section{AUTHORS' CONTRIBUTION:}

ZK: Manuscript writing along with conception and design of work and supervision.

$\mathrm{KI}$ : Manuscript writing, data analysis.
SK, IR: Data collection, revision of work.

A): Data analysis, manuscript correction.

\section{REFERENCES}

1. Tong H, Kwon D, Shi J, Sakai N, Enciso R, Sameshima GT. Mesiodistal angulation and faciolingual inclination of each whole tooth in 3-dimensional space in patients with nearnormal occlusion. Am J Orthod Dentofacial Orthop 2012; 141(5):604-17.

2. Nouri M, Hosseini SK, Asefi S, Abdi AH, Bagheban AA. Threedimensional measurement of tooth inclination: $A$ longitudinal study. Dent Res J (Isfahan) 2019; 16(4):225-32.

3. Delivanis HP, Kuftinec MM. Variation in morphology of the maxillary central incisors found in Class II, division 2 malocclusions. Am J Orthod 1980; 78(4):438-43.

4. Haralur SB, Lahig AA, Al Hudiry YA, Al-Shehri AH, Al-Malwi $A A$. Influence of post angulation between coronal and radicular segment on the fracture resistance of endodontically treated teeth. J Clin Diagn Res 2017; 11(8):ZC90ZC93.

5. Israr J, Bhutta N, Chatha MR. Comparison of collum angle of maxillary central incisors in Class II div $1 \& 2$ malocclusions. Pak Oral Dent J 2016; 36(1):91-4.

6. Heil A, Gonzalez EL, Hilgenfeld T, Kickingereder P, Bendszus M, Heiland S, et al. Lateral cephalometric analysis for treatment planning in orthodontics based on MRI compared with radiographs: A feasibility study in children and adolescents. PloS One 2017; 12(3):e0174524.

7. He D, Gu Y, Sun Y. Evaluation of aesthetic anteroposterior position of maxillary incisors in patients with extraction treatment using facial reference lines. J Int Med Res 2019; 47(7):2951-60.

8. Choi SH, Kim YH, Lee KJ, Hwang CJ. Effect of labiolingual inclination of a maxillary central incisor and surrounding alveolar bone loss on periodontal stress: A finite element analysis. Korean J Orthod 2016; 46(3):155-62.

9. Krogman WM. The face in profile. An anthropological x-ray investigation on swedish children and conscripts. By arne björk. Svensk Tandläkare-Tidskrift, Lund, vol. 40, No. 5B, 180 pp., 34 Tables, 65 Figures. 1947. Am J Phys Anthropol 1948; 6(1):121-5.

10. Bryant RM, Sadowsky PL, Dent M, Hazelrig JB. Variability in three morphologic features of the permanent maxillary central incisor. Am J Orthod Dentofacial Orthop 1984; 86(1):25-32.

11. Naini FB, Manouchehri S, Al-Bitar ZB, Gill DS, Garagiola U, Wertheim $D$. The maxillary incisor labial face tangent: Clinical evaluation of maxillary incisor inclination in profile smiling view and idealized aesthetics. Plast Reconstr Surg 2019; 41(1):1-7.

12. Shailaja AM, Gowda CN, Gowda S. The collum angle of maxillary central incisors in different skeletal malocclusions: A cephaometric study. Int J Applied Dental Sci 2016; 2(03):33-6.

13. Wang XM, Ma LZ, Wang J, Xue H. The crown-root morphology of central incisors in different skeletal malocclusions assessed with cone-beam computed tomography. Prog Orthod 2019; 20(1):20.

14. Ma ES. Differential CBCT analysis of collum angles in maxillary and mandibular anterior teeth in patients with 
different malocclusions[dissertation]. University of Nevada, Las Vegas 2016.

15. Jain $M$, Vyas $M$, Singh JR. Effect of crown angulation of maxillary incisor on effective arch perimeter. J Clin Diagnostic Res 2017; 11(6):ZC92-ZC6.

16. McIntyre GT, Millett DT. Lip shape and position in class ii division 2 malocclusion. Angle Orthod 2006; 76(5):739-44.

17. Robertson NR, Hilton R. Feature of the upper central incisors in class II, division 2. Angle Orthod 1965; 35:51-3.

18. Clelland NL, Gilat A. The effect of abutment angulation on stress transfer for an implant. J Prosthodont 1992; 1(1): 24-8.
19. Feres MF, Rozolen BS, Alhadlaq A, Alkhadra TA, El-Bialy T. Comparative tomographic study of the maxillary central incisor collum angle between class i, class II, division 1 and 2 patients. J Orthod 2018; 7:6.

20. Horiuchi A, Hotokezaka H, Kobayashi K. Correlation between cortical plate proximity and apical root resorption. Am J Orthod Dentofacial Orthop 1998; 114(3):311-8.

21. Pai SS, Panda S, Pai V, Anandu M, Vishwanath E, Suhas AS. Effects of labial and lingual retraction and intrusion force on maxillary central incisor with varying collum angles: A three-dimensional finite elemental analysis. J Indian Orthod Soc 2017; 51:28-37. 